\title{
The effects of maternal and infant vitamin A supplementation on vitamin A status: a randomised trial in Kenya
}

\author{
R. A. Ayah ${ }^{1,2}$, D. L. Mwaniki ${ }^{1}$, P. Magnussen ${ }^{3}$, A. E. Tedstone ${ }^{2}$, T. Marshall ${ }^{2}$, D. Alusala ${ }^{4}$, A. Luoba ${ }^{4}$, \\ P. Kaestel ${ }^{5}$, K. F. Michaelsen ${ }^{5}$ and H. Friis ${ }^{5 *}$ \\ ${ }^{1}$ Centre for Public Health Research, Kenya Medical Research Institute, Box 20752, Nairobi 00202, Kenya \\ ${ }^{2}$ Department of Epidemiology and Population Health, London School of Hygiene and Tropical Medicine, Keppel Street, London \\ WC1E 7HT, UK \\ ${ }^{3}$ DBL Institute of Health Research and Development, Charlottenlund, Denmark \\ ${ }^{4}$ Division of Vector Borne Diseases, Ministry of Health, PO Box 20750, Nairobi 00202, Kenya \\ ${ }^{5}$ Department of Human Nutrition, Faculty of Life Sciences, University of Copenhagen, Rolighedsvej 30, DK-1958 \\ Frederiksberg, Denmark
}

(Received 7 June 2006 - Revised 4 February 2007 - Accepted 6 February 2007)

\begin{abstract}
Postpartum vitamin A supplementation of mothers and infants is recommended, but the efficacy has been questioned. In this double-blind, placebocontrolled trial, Kenyan mother-infant pairs were randomised to maternal vitamin A ( $400000 \mathrm{IU})$ or placebo $<24 \mathrm{~h}$ postpartum, and infant vitamin A (100000 IU) or placebo at 14 weeks. Milk retinol was determined at weeks 4, 14 and 26, and maternal and infant serum retinol at weeks 14 and 26. Infant retinol stores were assessed at week 26, using a modified relative dose response (MRDR) test. Among 564 women, serum retinol at 36 weeks gestation was 0.81 (SD 0.21$) \mu \mathrm{mol} / \mathrm{l}$, and $33.3 \%$ were $<0.7 \mu \mathrm{mol} / \mathrm{l}$. Maternal serum retinol was not different between groups, but milk retinol was higher in the vitamin A group: $(0.67 v .0 .60 \mu \mathrm{mol} / 1 ; 0.52 v .0 .44 \mu \mathrm{mol} / \mathrm{l} ; 0.50 v .0 .44 \mu \mathrm{mol} / 1$ at 4,14 and 26 weeks, respectively). When expressed per gram fat, milk retinol was higher in the vitamin A group only at 4 weeks. Infant serum retinol was not different between groups. However, although most infants had deficient vitamin A stores (MRDR $>0.06 \%$ ) at 26 weeks, vitamin A to infants, but not mothers, resulted in a lower proportion of infants with deficient vitamin A stores $(69 v .78 \%)$. High-dose postpartum vitamin A supplementation failed to increase serum retinol and infant stores, despite modest effects on milk retinol. Infant supplementation, however, increased stores. There is a need for a better understanding of factors affecting absorption and metabolism of vitamin A.
\end{abstract}

Vitamin A: Supplementation: Postpartum: Breast milk: Kenya

Vitamin A deficiency is widespread among women of reproductive age and children in low-income countries (Humphrey et al. 1992; West, 2002), and regular high-dose vitamin A supplementation has been shown to reduce mortality among children from 6 months to 5 years (Fawzi et al. 1993). Assuming similar survival benefits for young infants, the research priority has shifted towards development of interventions to improve vitamin A status in the first 6-9 months of life.

Maternal vitamin A supplementation during the immediate postpartum period is a potentially effective strategy for simultaneously improving the vitamin A status of the women and their breast-fed infants (Stoltzfus et al. 1993; World Health Organization, 1998). However, studies have suggested that the recommended vitamin A dose of $200000 \mathrm{IU}$ is inadequate (Rice et al. 1999), even in combination with $25000 \mathrm{IU}$ given to infants at 6, 10 and 14 weeks (World Health Organization/CHD, 1998). It has therefore been suggested that the recommendation should be changed to 400000 IU vitamin A given as two doses (Ross, 2002).

The present study set out to assess the effects of high-dose postpartum maternal supplementation with $400000 \mathrm{IU}$ and infant supplementation with $100000 \mathrm{IU}$ at 14 weeks of age, on maternal and infant vitamin A status in the 6-month postpartum period.

\section{Subjects and methods}

\section{Study design}

The study was a randomised, placebo-controlled, doubleblind, two-by-two factorial trial, conducted between July 1999 and November 2001. The mothers were randomly allocated $400000 \mathrm{IU}$ vitamin A (A) or placebo (P) within $24 \mathrm{~h}$ of delivery, and their infants were randomly allocated $100000 \mathrm{IU}$ vitamin A (a) or placebo (p) at 14 weeks of age,

\footnotetext{
Abbreviations: ACT, $\alpha_{1}$-antichymotrypsin; MRDR, modified relative dose response.

* Corresponding author: Prof. Henrik Friis, fax +45 3528 2469, email hfr@life.ku.dk
} 
when the diphtheria-pertussis-tetanus and oral polio vaccines were given. Thus, there were four combinations of the two placebo-controlled interventions: maternal and infant vitamin A supplement (Aa), maternal vitamin $\mathrm{A}$ and infant placebo supplement (Ap), maternal placebo and an infant vitamin A supplement $(\mathrm{Pa})$, and placebo to both mother and infant $(\mathrm{Pp})$. The effects of the maternal intervention were assessed through determination of maternal serum retinol at weeks 14 and 26 postpartum, and breast milk retinol at weeks 4, 14 and 26. The effects of both interventions were assessed by infant vitamin A status determined by serum retinol at weeks 14 and 26 week and the modified relative dose response test (MRDR) at week 26.

\section{Study area and population}

The study was conducted in Bondo District, rural western Kenya, at the shores of Lake Victoria approximately $1200 \mathrm{~m}$ above sea level. The population practise subsistence farming and fishing. The main crops grown are maize, finger millet, cassava, sorghum, pulses and sweet potatoes. Vitamin A-rich foods, predominantly from plant sources, such as mangoes, papaya and dark green leafy vegetables are readily available but not widely consumed. The prevalence of HIV infection among antenatal attendees was above $28 \%$ at the time of the study (National AIDS Control Programme, 2001).

After informed consent, all women less than 24 weeks pregnant attending antenatal health care were invited to participate in the study. Gestational age was assessed by ultrasonography. A baseline interview about obstetric history and socio-demography was conducted, and anthropometric data were collected. A blood sample was collected and kept in a cool box at $4-8^{\circ} \mathrm{C}$ during transport to the laboratory for later serum retinol analysis. At 36 weeks gestation, another blood sample was drawn for analysis of serum retinol, which was considered the baseline.

We assumed that the standard deviations of maternal and infant serum retinol at 3 months and of infant serum retinol at 6 months postpartum were not greater than $0.5 \mu \mathrm{mol} / 1$ (Stoltzfus et al. 1993). We therefore needed to recruit 250 women in each group to detect a $0.17 \mu \mathrm{mol} / 1$ difference with $90 \%$ power and $95 \%$ confidence, while allowing for a $20 \%$ loss to follow-up. Assuming an interaction between maternal and infant supplementation, we would be able to detect a $0.23 \mu \mathrm{mol} / \mathrm{l}$ difference in infant serum retinol at 26 weeks of age between the four subgroups of infants.

\section{Randomisation and intervention}

Enrolment into the trial and randomisation only took place after delivery of a live singleton baby. Hoffmann La Roche Ltd (Basel, Switzerland) prepared and supplied the vitamin A and identical-looking placebo supplements as oily capsules in brown bottles coded as X or Y. To avoid mistakes between maternal and infant doses, maternal capsules (two capsules containing $200000 \mathrm{IU}$ dose or placebo) were bright red, while infant capsules (one containing $100000 \mathrm{IU}$ dose or placebo) were blue. Two random sequences of $\mathrm{X}$ and $\mathrm{Y}$ were prepared, one for the mothers and one for the infants. Identification numbers from 1 to 700 were assigned consecutively to each of the two lists and mother-infant pairs of capsules were packaged in zip-lock bags numbered from 1 to 700 and kept $\left(4^{\circ} \mathrm{C}\right)$ in batches of ten. The randomisation codes were concealed for the entire trial duration and only revealed after completion of data analysis.

As part of the national antenatal case guidelines all pregnant women received presumptive malarial treatment in their second and third trimesters. Further, iron and folic acid were given according to national guidelines. All the infants received $100000 \mathrm{IU}$ vitamin A after the trial, at 8 months of age. The trial was conducted prior to the availability of HIV testing and antiretroviral prophylaxis for antenatal women in publicsector facilities in western Kenya.

\section{Examinations, storage and analysis of biological specimens}

The data collected at week 36 during gestation served as the baseline. Study outcomes were assessed at weeks 4, 14 and 26 postpartum. Maternal height was measured without shoes to the nearest $0 \cdot 1 \mathrm{~cm}$ using a portable height measure (Leicester portable height measure; CMS, London, UK). Maternal body weight was measured in light clothing to the nearest $100 \mathrm{~g}$ using an electronic scale (UNISCALE; UNICEF, Copenhagen, Denmark).

All biological specimens were stored at $-196^{\circ} \mathrm{C}$ for 3 months, before transfer to the laboratory in Nairobi where they were stored at $-20^{\circ} \mathrm{C}$ for a maximum of 9 months before analysis. Serum concentrations of retinol were measured in non-fasting venous blood using HPLC (Hitachi Ltd, Tokyo, Japan) with retinyl acetate as internal standard, and hexane as the extracting solvent. The retinol standard curve was prepared from known concentrations of retinol against peak area ratio of retinol/retinyl acetate with detection wavelength at $325 \mathrm{~nm}$. Serum retinol concentration $<0.7 \mu \mathrm{mol} / 1$ was used to define low vitamin A status in both mothers and infants (World Health Organization, 1996).

For the MRDR analysis conducted in infants at 26 weeks, $5 \mathrm{ml}$ venous blood were drawn $4 \mathrm{~h}$ after oral ingestion of $5 \cdot 3 \mu \mathrm{mol} 3$,4-didehydroretinol administered directly into the infants mouth (Tanumihardjo et al. 1996). The infant was breast-fed on demand during the $4 \mathrm{~h}$ waiting period. Serum was extracted and analysed as normal serum samples with the only exception that the wavelength used to detect retinol, retinyl acetate (internal standard) and 3,4-didehydroretinol was $350 \mathrm{~nm}$. Standard curves were prepared for both 3,4-didehydroretinol and retinol using known concentrations against peak area ratio to internal standard (retinyl acetate).

A sample of $2-5 \mathrm{ml}$ foremilk was obtained from each mother by manual expression, after at least $1 \mathrm{~h}$ without nursing. The milk samples were kept cool until determination of milk fat within $4 \mathrm{~h}$ of collection and before freezing. Milk fat was determined by the creamatocrit method (Lucas et al. 1978) before storage. After thawing, to release retinol from fatty acids in milk, the samples were saponified before extraction with 3,4-didehydroretinol serving as the internal standard. After saponification with potassium hydroxide $\left(\mathrm{KOH}-\mathrm{H}_{2} \mathrm{O}\right.$, $60: 40$, w/v) at $60^{\circ} \mathrm{C}$ for $30 \mathrm{~min}$ the sample was cooled and extracted twice with hexane. After evaporation, the residue was reconstituted with mobile phase and injected into the HPLC system. The retinol standard curve was prepared using known concentrations of retinol against retinol/3,4-didehydroretinol peak area ratio when detected at $325 \mathrm{~nm}$. The retinol content in milk per volume $(\mu \mathrm{mol} / \mathrm{l})$ and per gram of 
milk fat $(\mu \mathrm{mol} / \mathrm{g})$ were calculated. According to WHO criteria, values $\leq 1.05 \mu \mathrm{mol} / \mathrm{l}$ and $\leq 0.28 \mu \mathrm{mol} / \mathrm{g}$ fat were considered low (World Health Organization, 1996).

Serum concentrations of the acute-phase protein $\alpha_{1}$-antichymotrypsin (ACT) and of ferritin were measured by automated turbidity (Cobas Mira Plus; Roche, Basel, Switzerland). Rabbit antihuman ACT (DAKO, Glostrup, Denmark) was used to precipitate ACT and turbidity was measured at $345 \mathrm{~nm}$ after incubation for $8.3 \mathrm{~min}$ at $37^{\circ} \mathrm{C}$. The results were given as $\mathrm{g} / \mathrm{l}$ serum on the basis of a standard curve from commercial calibrators (DAKO). Serum ferritin was measured by a fluoroimmunoassay kit (DELFIA Ferritin; Wallac, Turku, Finland) with the detection based on a europium-labelled monoclonal antibody against human ferritin. The detection limit was $0.5 \mu \mathrm{g} / \mathrm{l}$. The accuracy was confirmed by participation in a national control program (Danish Institute for External Quality Assurance (DEKS), Denmark).

\section{Statistical analyses}

Data were checked for reasonably normal distribution using cumulative normal plots. $t$ test and $\chi^{2}$ test were used to test for differences in means and proportions, respectively. Differences between baseline and week 14 or 26 postpartum were tested for each treatment group using paired $t$ tests. Pearson's $\chi^{2}$ test was used to test for differences in proportions between the two groups, or when numbers were small with Fisher's exact test.

In linear regression, the serum retinol deficits associated with elevated serum ACT between 0.3-0.35, 0.35-0.4, 0.4$0.5,0.5-0.6$ and above $0.6 \mathrm{~g} / 1$ were estimated, and baseline serum retinol then adjusted accordingly. The effects of supplementation on maternal and infant serum retinol were controlled for adjusted baseline maternal serum retinol, as well as for elevated serum ACT, using dummy variables, at the time the end-point sample was taken.

All analyses were by intention-to-treat. The level of significance used was $0 \cdot 05$.

\section{Ethical permissions}

Ethical permissions to conduct the present study were obtained from the ethics committees of the Kenya Medical Research Institute, the London School of Hygiene and Tropical Medicine and the Danish Central Medical Ethics Committee.

\section{Results}

During pregnancy 651 women were identified as eligible and recruited into the study. At the time of delivery, 584 were still living in the study area, were willing to participate in the trial and had delivered live singleton babies. Eventually, 564 were enrolled into the trial and randomised to receive vitamin A or placebo after delivery (Fig. 1). Among the 564 eventually randomised, the mean maternal age at recruitment between 14 and 24 weeks of gestation was 24.7 years (range 14-48 years), and $19.6 \%$ were primigravidae. Mean serum retinol was 0.96 (SD 0.27) $\mu \mathrm{mol} / \mathrm{l}$ at recruitment, and 0.81 (SD 0.21) $\mu \mathrm{mol} / \mathrm{l}$ at week 36 of gestation. Mean birth weight was $3 \cdot 11$ (SD 0.47$) \mathrm{kg}$, and $52 \%$ of the newborns were male.

Randomisation resulted in similar distribution of maternal and infant baseline characteristics in mother-infant pairs

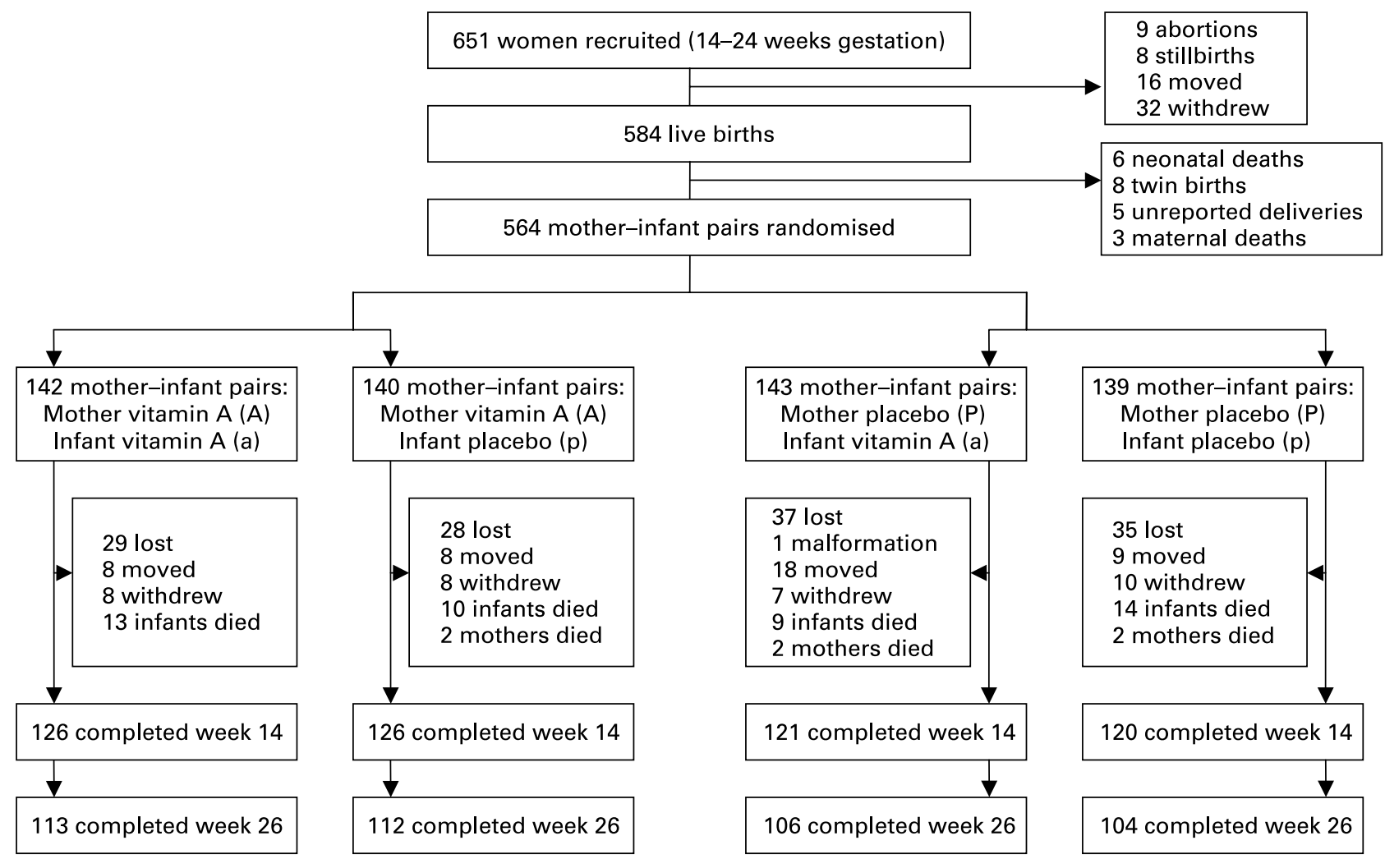

Fig. 1. Trial profile. 
allocated to maternal vitamin A supplementation or placebo (A or $\mathrm{P}$ ), and to the four combinations of maternal and infant supplementation (Aa, Ap, Pa or Pp) (Table 1).

There were no differences with respect to symptoms after 24 and $48 \mathrm{~h}$ between those allocated to placebo and vitamin A, neither among women or infants. Bulging fontanels was seen in four $(1.8 \%)$ infants receiving placebo and in eight $(3.6 \%)$ receiving vitamin A $(P=0.26)$. During the first 6 months, forty-six infants died. There were no differences by maternal or infant vitamin A supplementation: twenty-three had been randomised to maternal vitamin A and twentythree to maternal placebo supplementation $(P=1 \cdot 00)$. Similarly, twenty-two had been randomised to infant vitamin A and twenty-four to infant placebo supplementation $(P=0.70)$.

Maternal serum and breast milk retinol 14 weeks postpartum were determined in $71 \%$ (402) and $75 \%$ (422) of the 564 women, respectively, and infant MRDR at 26 weeks of age were determined in $64 \%$ (361) infants. There were no significant differences in maternal age, BMI, serum retinol at recruitment and 36 weeks of gestation, and birth weight, and proportion primigravidae, married or infant sex between mother-infant pairs lost to follow-up or those followed up for serum retinol at 14 weeks postpartum. However, those lost to follow-up for determination of breast milk retinol at 14 weeks and MRDR at 26 weeks had significantly lower birth weights than those followed up for these outcomes.

\section{Effects on maternal serum retinol}

The mean increments in maternal serum retinol from week 36 of gestation to 14 and 26 weeks postpartum were $0.22(95 \% \mathrm{CI}$ $0 \cdot 18,0 \cdot 26)$ and $0.14(95 \%$ CI $0 \cdot 10,0 \cdot 18) \mu \mathrm{mol} / 1$, respectively.
The effect of maternal vitamin A supplementation was expressed as the difference (vitamin A - placebo) in increase in serum retinol from week 36 of gestation to 14 and 26 weeks postpartum. There were no effects of maternal vitamin A supplementation on increase in maternal serum retinol, neither at $14(0.05 \mu \mathrm{mol} / \mathrm{l} ; 95 \% \mathrm{CI}-0.03,0.12)$ nor $26(-0.02 \mu \mathrm{mol} / \mathrm{l}$; $95 \%$ CI $-0 \cdot 10,0 \cdot 06$ ) weeks postpartum (Table 2). The estimates did not change after controlling for adjusted baseline serum retinol, and elevated serum ACT at follow-up (data not shown).

To assess if the effect of maternal vitamin A supplementation depended on levels of background characteristics (serum retinol, ferritin and ACT, gravidity, birth weight, sex), tests for interactions were done using multiple linear regression analysis. The effects of $0.11 \mu \mathrm{mol} / \mathrm{l}(95 \% \mathrm{CI}-0.005,0 \cdot 22, P=0.06)$ among those with serum retinol below $0.70 \mu \mathrm{mol} / 1$ at week 36 of gestation, and $0.01 \mu \mathrm{mol} / 1$ (95\% CI $-0.08,0 \cdot 10, P=0.83)$ among those with serum retinol at or above $0.7 \mu \mathrm{mol} / 1 \mathrm{did}$ not differ significantly (interaction, $P=0 \cdot 20$ ).

The effect of maternal vitamin A supplementation depended on serum ferritin at week 36 of gestation (interaction, $P=0.025)$, due to a greater effect in those with serum ferritin above $12 \mu \mathrm{g} / \mathrm{l}(0.13 ; 95 \%$ CI $0.02,0 \cdot 25, P=0.02)$ compared to those below $(-0.04 ; 95 \%$ CI $-0.14,0.06, P=0.47)$. The effect of maternal vitamin A supplementation was $0 \cdot 11 \mu \mathrm{mol} / 1(95 \% \mathrm{CI}-0.002,0.21, P=0.055)$ among mothers to infants with birth weight below $3000 \mathrm{~g}$, and $-0.03(95 \% \mathrm{CI}$ $-0.14,0.07, P=0.55)$ among mothers to infants with birth weight above $3000 \mathrm{~g}$, but this difference was not significant (interaction, $P=0 \cdot 09$ ). There were no interactions between maternal supplementation and gravidity, serum ACT and infant sex.

Table 1. Baseline maternal and infant characteristics by maternal and infant supplementation group

\begin{tabular}{|c|c|c|c|c|c|c|c|c|}
\hline & \multicolumn{8}{|c|}{ Maternal supplementation } \\
\hline & \multicolumn{4}{|c|}{ Vitamin A (A) ( $n$ 282) } & \multicolumn{4}{|c|}{ Placebo (P) (n 282) } \\
\hline & \multicolumn{2}{|c|}{$\begin{array}{l}\text { Infant, vitamin } \mathrm{A}(\mathrm{a}) \\
(n 142)\end{array}$} & \multicolumn{2}{|c|}{$\begin{array}{c}\text { Infant, placebo }(p) \\
(n \text { 140) }\end{array}$} & \multicolumn{2}{|c|}{$\begin{array}{l}\text { Infant, vitamin (a) } \\
(n \text { 143) }\end{array}$} & \multicolumn{2}{|c|}{$\begin{array}{c}\text { Infant, placebo (p) } \\
(n \text { 139) }\end{array}$} \\
\hline & Mean & SD & Mean & SD & Mean & SD & Mean & SD \\
\hline \multicolumn{9}{|l|}{ Maternal } \\
\hline \multicolumn{9}{|l|}{ Weeks $16-24$ of gestation } \\
\hline Maternal age (years) & $24 \cdot 3$ & $6 \cdot 5$ & $25 \cdot 5$ & $7 \cdot 2$ & $24 \cdot 6$ & $6 \cdot 2$ & 24.4 & $6 \cdot 4$ \\
\hline Married (\%) & $80 \cdot 7$ & & $83 \cdot 6$ & & $86 \cdot 6$ & & $80 \cdot 4$ & \\
\hline Gravidity* & 2 & $1-4$ & 2 & $1-4$ & 2 & $1-4$ & 2 & $1-4$ \\
\hline Weight (kg) & $58 \cdot 0$ & $7 \cdot 3$ & $57 \cdot 8$ & 7.5 & $58 \cdot 8$ & $8 \cdot 0$ & $58 \cdot 2$ & 7.5 \\
\hline Height (cm) & $162 \cdot 4$ & $5 \cdot 9$ & $161 \cdot 7$ & $5 \cdot 9$ & $161 \cdot 9$ & $6 \cdot 4$ & 162,4 & $5 \cdot 8$ \\
\hline BMI $\left(\mathrm{kg} / \mathrm{m}^{2}\right)$ & $22 \cdot 0$ & $2 \cdot 2$ & $22 \cdot 1$ & $2 \cdot 5$ & $22 \cdot 4$ & $2 \cdot 4$ & $22 \cdot 1$ & $2 \cdot 4$ \\
\hline Serum retinol $(\mu \mathrm{mol} / \mathrm{l}) \dagger$ & 0.91 & 0.25 & 0.97 & 0.27 & 0.97 & 0.26 & 0.96 & 0.28 \\
\hline \multicolumn{9}{|l|}{ Week 36 of gestation } \\
\hline Serum retinol $(\mu \mathrm{mol} / \mathrm{l}) \dagger$ & 0.79 & 0.20 & 0.81 & 0.21 & 0.82 & 0.18 & 0.84 & $2 \cdot 6$ \\
\hline Serum ACT $(\mathrm{g} / \mathrm{l})^{\star} \ddagger$ & 0.32 & $0.28-0.38$ & 0.31 & $0.28-0.37$ & 0.31 & $0.28-0.37$ & 0.32 & $0.27-0.38$ \\
\hline Serum ferritin $(\mu \mathrm{g} / \mathrm{l})^{\star} \ddagger$ & $9 \cdot 8$ & $6 \cdot 7-19 \cdot 9$ & $10 \cdot 4$ & $6 \cdot 9-20 \cdot 4$ & $12 \cdot 3$ & $6 \cdot 5-25 \cdot 4$ & $10 \cdot 4$ & $6 \cdot 5-21 \cdot 8$ \\
\hline \multicolumn{9}{|l|}{ Infant } \\
\hline Birth weight (kg) & $3 \cdot 10$ & 0.50 & $3 \cdot 14$ & 0.46 & $3 \cdot 13$ & 0.44 & 3.08 & 0.48 \\
\hline Male sex (\%) & $57 \cdot 0$ & & $46 \cdot 9$ & & $47 \cdot 6$ & & $56 \cdot 5$ & \\
\hline
\end{tabular}

ACT, $\alpha_{1}$-antichymotrypsin.

${ }^{*}$ Median and interquartile range.

† Data available for $121(\mathrm{~A} / \mathrm{a}), 120(\mathrm{~A} / \mathrm{p}), 130(\mathrm{P} / \mathrm{a}), 119(\mathrm{P} / \mathrm{p})$ at week 16-24, and $94(\mathrm{~A} / \mathrm{a}), 99(\mathrm{~A} / \mathrm{p}), 97(\mathrm{P} / \mathrm{a}), 83(\mathrm{P} / \mathrm{p})$ at week 36.

‡Data available for $126(\mathrm{~A} / \mathrm{a}), 128(\mathrm{~A} / \mathrm{p}), 118(\mathrm{P} / \mathrm{a}), 110(\mathrm{P} / \mathrm{p})$. 
Table 2. Maternal serum retinol concentration at week 36 of gestation, and at weeks 14 and 26 postpartum

\begin{tabular}{|c|c|c|c|c|c|c|c|}
\hline & \multicolumn{2}{|c|}{ Vitamin A } & \multicolumn{2}{|c|}{ Placebo } & \multicolumn{2}{|c|}{$\begin{array}{c}\text { Difference } \\
\text { (vitamin A- placebo) }\end{array}$} & \multirow[b]{2}{*}{$P$} \\
\hline & Mean & $95 \% \mathrm{Cl}$ & Mean & $95 \% \mathrm{Cl}$ & Mean & $95 \% \mathrm{Cl}$ & \\
\hline Week 36 of gestation & $n 193$ & & $n 180$ & & & & \\
\hline Serum retinol $(\mu \mathrm{mol} / \mathrm{l})$ & 0.80 & & 0.83 & & - & & - \\
\hline$<0.7(\%)^{*}$ & $36 \cdot 8$ & & $27 \cdot 2$ & & - & & - \\
\hline Week 14 postpartum & $n 205$ & & $n 197$ & & & & \\
\hline Serum retinol $(\mu \mathrm{mol} / \mathrm{l})$ & 1.05 & $1.02,1.08$ & 1.01 & $0.97,1.05$ & 0.04 & $-0.01,0.09$ & 0.13 \\
\hline$<0.7(\%)^{\star}$ & 8.7 & $5 \cdot 3,13 \cdot 5$ & $13 \cdot 7$ & $9 \cdot 2,19 \cdot 3$ & -4.9 & $-11 \cdot 1,0.01$ & 0.12 \\
\hline Week 26 postpartum & $n 148$ & & $n 143$ & & & & \\
\hline Serum retinol $(\mu \mathrm{mol} / \mathrm{l})$ & 0.96 & $0.91,1.00$ & 0.98 & $0.93,1.02$ & -0.02 & $-0.08,0.04$ & 0.50 \\
\hline$<0.7(\%)^{*}$ & 11.5 & $6 \cdot 8,17 \cdot 8$ & $14 \cdot 0$ & $8 \cdot 8,20 \cdot 8$ & -2.5 & $-10 \cdot 2,5 \cdot 2$ & 0.52 \\
\hline \multicolumn{8}{|l|}{ Increase from 36 weeks } \\
\hline To week 14 & $n 134$ & & $n 122$ & & & & \\
\hline Serum retinol $(\mu \mathrm{mol} / \mathrm{l})$ & 0.24 & $0 \cdot 19,0.30$ & 0.20 & $0 \cdot 15,0.25$ & 0.05 & $-0.03,0.12$ & 0.21 \\
\hline To week 26 & $n 91$ & & $n 82$ & & & & \\
\hline Serum retinol $(\mu \mathrm{mol} / \mathrm{l})$ & $0 \cdot 13$ & $0.07,0.19$ & $0 \cdot 15$ & $0 \cdot 10,0 \cdot 20$ & -0.02 & $-0.10,0.06$ & 0.58 \\
\hline
\end{tabular}

*Proportion.

\section{Effects on breast milk retinol}

Mean breast milk retinol was $0.64 \mu \mathrm{mol} / \mathrm{l}(95 \% \mathrm{CI} 0.61,0.67)$ at 4 weeks, and then declined to $0.48 \mu \mathrm{mol} / 1$ (95\% CI 0.46 , $0.51)$ and $0.47 \mu \mathrm{mol} / 1$ (95\% CI $0.45,0.50)$ at 14 and 26 weeks postpartum, respectively. The proportions with values below $1.05 \mu \mathrm{mol} / \mathrm{l}$ were $88.7 \%$ at 4 weeks, and above $96 \%$ at 14 and 26 weeks. All women had milk retinol per gram fat below the cut-off of $0.28 \mu \mathrm{mol} / \mathrm{g}$ at all time-points. Nevertheless, vitamin A supplementation was associated with significantly higher milk retinol per volume at 4,14 and 26 weeks postpartum, and higher milk retinol expressed per gram fat at week 4, but not at weeks 14 and 26 (Table 3). There were no interactions with gravidity, maternal baseline serum retinol and ferritin, birth weight and infant sex, and the estimates did not change after controlling for adjusted baseline serum retinol, and elevated serum ACT at 14 and 26 weeks follow-up (data not shown).
Infant serum retinol and modified relative dose response

Mean serum retinol was $0.92 \mu \mathrm{mol} / 1$ (95\% CI $0.89,0.94)$ among 317 infants examined at 14 weeks, and $1.04 \mu \mathrm{mol} / \mathrm{l}$ (95\% CI 1.01, 1.07) among 280 infants examined at 26 weeks of age. At 14 weeks, there was no significant difference in infant serum retinol between those of mothers allocated to placebo and vitamin A. At 26 weeks, there were no differences in infant serum retinol between infants of mothers allocated to placebo and vitamin $\mathrm{A}$, or between infants receiving placebo or vitamin A (interaction, $P=0.09$ ). The estimates did not change after controlling for adjusted maternal baseline serum retinol, and elevated infant serum ACT at follow-up (data not shown).

MRDR ratio, a measure of vitamin A stores, was determined among 361 infants at 26 weeks of age. The mean MRDR ratio was 0.081 (95\% CI $0.077,0.084)$, with $74.5 \%$ having values above 0.06 used to define low vitamin A

Table 3. Milk retinol and fat concentrations at 4,14 and 26 weeks postpartum

\begin{tabular}{|c|c|c|c|c|c|c|c|}
\hline & \multicolumn{2}{|c|}{ Vitamin A } & \multicolumn{2}{|c|}{ Placebo } & \multicolumn{2}{|c|}{$\begin{array}{c}\text { Difference } \\
\text { (vitamin A - placebo) }\end{array}$} & \multirow[b]{2}{*}{$P$} \\
\hline & Mean & $95 \% \mathrm{Cl}$ & Mean & $95 \% \mathrm{Cl}$ & Mean & $95 \% \mathrm{Cl}$ & \\
\hline Week 4 postpartum & n 215 & & n 199 & & & & \\
\hline Milk retinol $(\mu \mathrm{mol} / \mathrm{l})$ & 0.67 & $0.63,0.72$ & 0.60 & $0.56,0.65$ & 0.07 & $0.004,0.14$ & 0.04 \\
\hline$<1.05(\%)^{\star}$ & $85 \cdot 6$ & $80 \cdot 2,90 \cdot 0$ & $92 \cdot 0$ & $87 \cdot 3,95 \cdot 3$ & $-6 \cdot 4$ & $-12 \cdot 5,-0.2$ & 0.03 \\
\hline Milk fat $(\mathrm{g} / \mathrm{l})$ & 34.6 & $31.9,37.2$ & $37 \cdot 3$ & $34.5,40 \cdot 0$ & $-2 \cdot 7$ & $-6 \cdot 5,1 \cdot 1$ & 0.16 \\
\hline Milk retinol/fat $(\mu \mathrm{mol} / \mathrm{g}) \dagger$ & 0.025 & $0.022,0.028$ & 0.019 & $0.016,0.023$ & 0.006 & $0.001,0.01$ & 0.02 \\
\hline Week 14 postpartum & n 221 & & n 201 & & & & \\
\hline Milk retinol $(\mu \mathrm{mol} / \mathrm{l})$ & 0.52 & $0.49,0.55$ & 0.44 & $0.40,0.47$ & 0.08 & $0.03,0.13$ & 0.001 \\
\hline Milk fat (g/l) & 31.5 & $29 \cdot 0,34 \cdot 1$ & $29 \cdot 8$ & $27 \cdot 4,32 \cdot 2$ & 1.7 & $-1 \cdot 8,5 \cdot 3$ & 0.33 \\
\hline Milk retinol/fat $(\mu \mathrm{mol} / \mathrm{g}) \dagger$ & 0.020 & $0.018,0.021$ & 0.019 & $0.017,0.021$ & 0.001 & $-0.002,0.004$ & 0.43 \\
\hline Week 26 postpartum & n 184 & & $n 170$ & & & & \\
\hline Milk retinol $(\mu \mathrm{mol} / \mathrm{l})$ & 0.50 & $0.46,0.53$ & 0.44 & $0.41,0.48$ & 0.05 & $0.003,0.10$ & 0.04 \\
\hline Milk fat $(\mathrm{g} / \mathrm{l})$ & $31 \cdot 3$ & $28 \cdot 8,33 \cdot 8$ & $30 \cdot 1$ & $27 \cdot 4,32 \cdot 9$ & $1 \cdot 1$ & $-2 \cdot 6,4.9$ & 0.54 \\
\hline Milk retinol/fat $(\mu \mathrm{mol} / \mathrm{g}) \dagger$ & 0.020 & $0.018,0.022$ & 0.019 & $0.017,0.021$ & 0.001 & $-0.001,0.004$ & 0.31 \\
\hline
\end{tabular}

* Proportion.

† Due to missing creamatocrit data, $n$ values in placebo and vitamin A groups were lower at week 4 (136 and 165), 14 (168 and 181) and 26 (142 and 152). 
Table 4. Infant serum retinol at 14 and 26 weeks of age, and modified relative dose response (MRDR) ratio according to maternal and infant treatment group

\begin{tabular}{|c|c|c|c|c|c|c|c|c|c|c|c|c|c|c|}
\hline & \multicolumn{8}{|c|}{ Intervention group (maternal/infant) ${ }^{*}$} & \multirow{2}{*}{\multicolumn{2}{|c|}{$\frac{\text { Difference } \dagger}{\text { Infant }(a-p)}$}} & \multirow[b]{3}{*}{$P$} & \multirow{2}{*}{\multicolumn{2}{|c|}{$\frac{\text { Difference } \dagger}{\text { Maternal }(A-P)}$}} & \multirow[b]{3}{*}{$P$} \\
\hline & \multicolumn{2}{|c|}{$\mathrm{A} / \mathrm{a}(n$ 142) } & \multicolumn{2}{|c|}{$\mathrm{A} / \mathrm{p}(n 140)$} & \multicolumn{2}{|c|}{$\mathrm{P} / \mathrm{a}(n 143)$} & \multicolumn{2}{|c|}{$\mathrm{P} / \mathrm{p}(n 139)$} & & & & & & \\
\hline & Mean & $95 \% \mathrm{Cl}$ & Mean & $95 \% \mathrm{Cl}$ & Mean & $95 \% \mathrm{Cl}$ & Mean & $95 \% \mathrm{Cl}$ & Mean & $95 \% \mathrm{Cl}$ & & Mean & $95 \% \mathrm{Cl}$ & \\
\hline \multicolumn{15}{|l|}{14 weeks } \\
\hline $\begin{array}{c}\text { Serum retinol } \\
(\mu \mathrm{mol} / \mathrm{l}) \ddagger\end{array}$ & 0.90 & $0.85,0.95$ & 0.92 & $0.87,0.96$ & 0.95 & $0.89,1.01$ & 0.90 & $0.86,0.93$ & - & & - & -0.02 & $-0.06,0.03$ & 0.51 \\
\hline$<0.7(\%) \ddagger$ & $19 \cdot 5$ & $0 \cdot 1,38 \cdot 9$ & $16 \cdot 7$ & $-3 \cdot 6,37 \cdot 0$ & $15 \cdot 5$ & $-5 \cdot 9,36 \cdot 9$ & $14 \cdot 0$ & $-5 \cdot 6,33 \cdot 6$ & - & & - & 3.5 & $-16 \cdot 6,23 \cdot 6$ & 0.45 \\
\hline \multicolumn{15}{|l|}{26 weeks } \\
\hline $\begin{array}{c}\text { Serum retinol } \\
(\mu \mathrm{mol} / \mathrm{l}) \S\end{array}$ & 1.02 & $0.97,1.07$ & 1.08 & $1.00,1 \cdot 15$ & 1.06 & $0.99,1.13$ & 1.02 & $0.97,1.06$ & -0.01 & $-0.07,0.05$ & 0.77 & 0.01 & $-0.05,0.07$ & 0.72 \\
\hline$<0.7(\%) \S$ & $4 \cdot 1$ & $-18 \cdot 3,26 \cdot 5$ & 8.0 & $-13 \cdot 7,29 \cdot 7$ & $6 \cdot 1$ & $-17 \cdot 3,29.5$ & $6 \cdot 1$ & $-17 \cdot 3,29.5$ & $-2 \cdot 1$ & $-24 \cdot 8,20 \cdot 6$ & 0.62 & 0.02 & $-5 \cdot 6,5 \cdot 7$ & 1.00 \\
\hline MRDR ratio & 0.076 & $0.069,0.082$ & 0.082 & $0.075,0.088$ & 0.073 & $0.067,0.079$ & 0.091 & $0.082,0.100$ & -0.012 & $-0.019,-0.005$ & 0.001 & -0.003 & $-0.010,0.004$ & 0.39 \\
\hline$\geq 0.06(\%) \|$ & $70 \cdot 4$ & $52 \cdot 8,89 \cdot 8$ & $80 \cdot 2$ & $62 \cdot 3,98 \cdot 1$ & $68 \cdot 5$ & $52 \cdot 6,86 \cdot 6$ & $76 \cdot 3$ & $58 \cdot 6,94 \cdot 0$ & -8.9 & $-19 \cdot 5,1 \cdot 7$ & 0.056 & 3.3 & $-7 \cdot 2,13 \cdot 8$ & 0.55 \\
\hline$\geq 0.12(\%) \|$ & $11 \cdot 3$ & $0 \cdot 8,21 \cdot 8$ & $10 \cdot 4$ & $0 \cdot 7,20 \cdot 0$ & 8.7 & $-1 \cdot 3,18 \cdot 7$ & $22 \cdot 6$ & $13 \cdot 5,31 \cdot 7$ & -6.5 & $-25 \cdot 8,12 \cdot 8$ & 0.09 & -4.9 & $-24 \cdot 1,14 \cdot 3$ & 0.21 \\
\hline \multicolumn{15}{|c|}{ Increase $14-26$ weeks } \\
\hline $\begin{array}{c}\text { Serum retinol } \\
(\mu \mathrm{mol} / /)\end{array}$ & 0.08 & $0.01,0.16$ & $0 \cdot 13$ & $0.05,0.22$ & 0.13 & $0.03,0.24$ & $0 \cdot 10$ & $0.04,0.16$ & -0.009 & $-0.087,0.068$ & 0.81 & -0.01 & $-0.08,0.07$ & 0.88 \\
\hline$<0.7(\%) q$ & $-15 \cdot 4$ & & -8.7 & & -9.4 & & -7.9 & & -4.5 & & 0.86 & -3.5 & & 0.58 \\
\hline
\end{tabular}

${ }^{*} \mathrm{P}$ is placebo and $\mathrm{A}$ is vitamin $\mathrm{A}$; uppercase letter denotes maternal and lowercase letter denotes infant supplementation.

†Difference between infants receiving vitamin $A$ minus placebo $(a-p)$ and infants whose mothers received vitamin $A$ minus placebo $(A-P)$.
† Mean serum retinol and proportion with low values at 14 weeks. Data available for $86(P / p), 78(A / p), 71(P / a), 82(A / a)$.

\$ Mean serum retinol and proportion with low values at 26 weeks. Data available for $66(\mathrm{P} / \mathrm{p}), 75(\mathrm{~A} / \mathrm{p}), 66(\mathrm{P} / \mathrm{a}), 73(\mathrm{~A} / \mathrm{a})$.

M Mean MRDR and proportion with high values at 26 weeks. Data available for $93(\mathrm{P} / \mathrm{p}), 96(\mathrm{~A} / \mathrm{p}), 92(\mathrm{P} / \mathrm{a}), 80(\mathrm{~A} / \mathrm{a})$.

9 Mean change in serum retinol and proportion with low values from 14-26 weeks. Data available for 55 (P/p), 46 (A/p), 40 (P/a), 49 (A/a). 
store. There was no interaction between maternal and infant supplementation $(P=0 \cdot 11)$, and only the main effects of maternal and infant supplementation are therefore presented. As seen from Table 4, maternal vitamin A supplementation had no effect. In contrast, infant vitamin A supplementation reduced MRDR ratios $(-0.012 ; 95 \% \mathrm{CI}-0.019,-0.005)$, and the proportion with high ratios $(-8.9 \% ; 95 \%$ CI $-19.5,1.7)$. Infant supplementation was associated with reduced risk of MRDR ratios above 0.06 (OR 0.66; $95 \% \mathrm{CI}$ $0.41,1 \cdot 05, P=0.08)$ and 0.12 (OR $0.56 ; 95 \%$ CI $0.30,1 \cdot 05$, $P=0 \cdot 07)$. There was no confounding or interaction with gravidity, maternal serum retinol, ferritin and ACT, birth weight or sex.

\section{Discussion}

A maternal postpartum vitamin A dose of 400000 IU (Ross, 2002), given at once, failed to increase maternal serum retinol, but slightly increased breast milk retinol concentrations. The effect on breast milk retinol was not followed by effects on infant status. Nevertheless, supplementing the infants with $100000 \mathrm{IU}$ at 14 weeks increased vitamin A stores, as measured by the MRDR test, but had no effects on infant serum retinol.

\section{Maternal supplementation}

The modest effects on milk retinol and lack of effects on maternal serum retinol and infant stores are in contrast to those from trials among Indonesian and Bangladeshi women.

In Indonesia (Stoltzfus et al. 1993), a single dose of 300000 IU given 1-3 weeks postpartum was shown to increase maternal serum and milk retinol, and infant stores for up to 6 months. In Bangladesh (Rice et al. 1999), a single postpartum dose of $200000 \mathrm{IU}$ vitamin A had no effects on maternal serum retinol, but had beneficial effects on maternal MRDR and milk retinol, which were followed by effects on infant serum retinol and MRDR at 6 months of age. As part of the Zimbabwe Vitamin A for Mothers and Babies trial to assess the effects of immediate postpartum mother-infant supplementation on infant mortality, $400000 \mathrm{IU}$ vitamin A given to the mother within $96 \mathrm{~h}$ postpartum seemed to increase serum retinol among HIV-uninfected mothers (Malaba et al. 2005).

In the present study, the lack of effect on maternal serum retinol is not likely explained by the limitations of serum retinol as a measure of vitamin A status. Serum retinol is homeostatically controlled across a wide range of liver stores (Olson, 1984), and declines in the presence of an acutephase response (Thurnham \& Singkamani, 1991). Nevertheless, the women in the present study had relatively low serum retinol levels that should be sensitive to changes in intake and status. Furthermore, we adjusted for elevated serum ACT in our analyses, to account for the effect of the acutephase response on serum retinol. The maternal supplement was followed by an increase in milk retinol, but only at 4 weeks postpartum when expressed relative to fat. Given the modest effects on milk retinol, it is not surprising that no effects were found on infant serum retinol and MRDR.

Alternatively, there could have been differences between the trials, with respect to factors impairing absorption and metabolisation of vitamin A. For example, inadequate intake of fat in the diet may have impaired absorption, and co-existing deficiency of zinc intake may have impaired synthesis of retinol binding protein and thus the mobilisation of vitamin A from the liver (Lonnerdal, 1998). Furthermore, the present data suggest that maternal iron status modified the effect of vitamin A supplementation on maternal serum retinol, in that the effect was significantly higher in women with nondepleted iron stores.

Another notable difference between the trials is that we supplemented the women within $24 \mathrm{~h}$ of delivery, whereas in the trials from Indonesia and Bangladesh, the supplements were administered between 1 and 3 weeks postpartum. Even uncomplicated parturition is precipitating a substantial acutephase response, which peaks within the first week postpartum ( $\mathrm{H}$ Friis, unpublished results). If an acute-phase response is impairing the absorption and metabolism of vitamin $\mathrm{A}$, then larger effects may be expected if the supplement is given when the acute-phase response is fading, such as towards the end of the 6-week infertile postpartum period within which it is now recommended to give vitamin A.

A major limitation of the present study is the lack of data on HIV status, despite an estimated prevalence above $28 \%$. While HIV infection is not likely to confound the present results, it is likely that HIV infection impairs absorption and increases requirements, and thus reduces the effect of vitamin A supplementation on measures of status. This was found in the Zimbabwe Vitamin A for Mothers and Babies trial, where serum retinol increased among HIV-uninfected, but not among HIV-infected women, after postpartum vitamin A supplementation (Zvandasara et al. 2006). Of greater concern, however, is if vitamin A supplementation when given to HIVinfected mothers has effects on breastfeeding-associated mother-to-child transmission and on mortality among HIVinfected children. Daily ante- and postnatal maternal supplementation with vitamin A given as preformed vitamin A and provitamin A carotenoids may increase mother-tochild HIV transmission (Fawzi et al. 2002), although this was not found in trials with similar interventions (Coutsoudis et al. 1999; Kumwenda et al. 2002). Also, recent data from the Zimbabwe Vitamin A for Mothers and Babies trial found no effects of maternal postpartum vitamin A supplementation on mother-to-child HIV transmission (Humphrey et al. 2006).

\section{Infant supplementation}

Infant supplement containing $100000 \mathrm{IU}$ vitamin A given at 14 weeks was neither associated with bulging fontanels and other acute signs, nor with mortality up to 6 months. Infant supplementation had no effect on serum retinol at 26 weeks, but increased the infant vitamin A stores, as assessed by the MRDR. This effect was in accord with the World Health Organization/CHD multi-country trial (1998), which found that a maternal postpartum supplement of $200000 \mathrm{IU}$ combined with infant supplement of $25000 \mathrm{IU}$ at 6,10 and 14 weeks reduced the proportion of infants with low serum retinol at 6 months.

While the benefit of regular high-dose vitamin A supplementation of older infants and young children $(6$ months to 5 years) on mortality is well established, data on the effect of vitamin A supplementation among young infants 
( $<6$ months) are inconsistent. Among infants of HIV-negative mothers, neonatal vitamin A supplementation (50000 IU as one or two doses) reduced mortality among Indonesian and Indian (Humphrey et al. 1996; Rahmathullah et al. 2003), but not among Zimbabwean infants (Malaba et al. 2005). In a study among young Indonesian infants, there were no overall effects on mortality of $50000 \mathrm{IU}(<1$ month) or $100000 \mathrm{IU}$ (1-5 months) (West et al. 1995). Similarly, no effects of 25000 IU given after 6,10 and 14 weeks on mortality were found in the World Health Organization/CHD study (1998). The Zimbabwe Vitamin A for Mothers and Babies trial found that among infants of HIV-positive mothers, the effect of neonatal vitamin A supplementation depended on the timing of infant HIV infection (Humphrey et al. 2006): there were no effects in infants found positive at birth, whereas mortality was reduced in those found negative at birth and positive at 6 weeks, and increased in those found negative at 6 weeks.

\section{Conclusion}

The aim of the present trial was to contribute to the development of feasible interventions to increase vitamin A status among young infants. The inadequate effect of increasing doses, and combining maternal and infant doses, and the inconsistent results from different trials, suggest that other factors may modify the absorption and metabolisation of vitamin A.

Furthermore, this and similar trials were based on the assumption that improved vitamin A status would reduce infant morbidity and mortality, similar to what has been shown among children between 6 months and 5 years. Emerging data, however, suggest that the effects of vitamin A interventions are not fully explained by their effect on status. The effects of a specific vitamin A intervention, both in terms of vitamin A status and morbidity and mortality, may be modified by co-existing nutritional deficiencies, the infectious disease pattern, recent immunisations and other factors. Recommendations should therefore be based on evidence for beneficial effects on morbidity and mortality, rather than on status.

\section{Acknowledgements}

We are indebted to the mothers of Yimbo for their patience and cooperation. Acknowledgement is made of the contribution of the entire KEDAHR research team both from CPHR, Nairobi and DVBD Kisumu, all the field assistants, traditional birth attendants, community nurses, data management and KEDAHR coordination personnel. In particular, we thank Ben Omondi, Felista King'ori and Washington Ochieng for technical assistance, and the Director of KEMRI for permission to publish. The study was supported by the Danish International Development Assistance through DBL-Institute for Health Research and Development (formerly Danish Bilharziasis Laboratory). R. Ayah was also supported by UNICEF/UNDP/World Bank/WHO Special Programme for Research and Training in Tropical Diseases (TDR). Hoffmann La Roche Ltd prepared and supplied the vitamin A and placebo capsules. A. E. Tedstone has an honorary position at the London School of Hygiene and Tropical Medicine.

\section{References}

Coutsoudis A, Pillay K, Spooner E, Kuhn L \& Coovadia HM (1999) Randomized trial testing the effect of vitamin A supplementation on pregnancy outcomes and early mother-to-child HIV-1 transmission in Durban, South Africa. South African Vitamin A Study Group. AIDS 13, 1517-1524.

Fawzi WW, Chalmers TC, Herrera MG \& Mosteller F (1993) Vitamin A supplementation and child mortality. A meta-analysis. JAMA 269, 898-903.

Fawzi W, Msamanga G, Spiegelman D, et al. (2002) Transmission of HIV-1 through breastfeeding among women in Dar es Salaam, Tanzania. J Acquir Immune Defic Syndr 31, 331-338.

Humphrey JH, Agoestina T, Wu L, et al. (1996) Impact of neonatal vitamin A supplementation on infant morbidity and mortality. J Pediatr 128, 489-496.

Humphrey JH, Iliff PJ, Marinda ET, et al. (2006) Effects of a single large dose of vitamin A, given during the postpartum period to HIV-positive women and their infants, on child HIV infection, HIV-free survival, and mortality. J Infect Dis 193, $860-871$.

Humphrey JH, West KP Jr \& Sommer A (1992) Vitamin A deficiency and attributable mortality among under-5-year-olds. Bull World Health Organ 70, 225-232.

Kumwenda N, Miotti PG, Taha TE, et al. (2002) Antenatal vitamin A supplementation increases birth weight and decreases anemia among infants born to human immunodeficiency virus-infected women in Malawi. Clin Infect Dis 35, 618-624.

Lonnerdal B (1998) Zinc metabolism during pregnancy - interactions with vitamin A. Bibl Nutr Diet 54, 93-102.

Lucas A, Gibbs JA, Lyster RL \& Baum JD (1978) Creamatocrit: simple clinical technique for estimating fat concentration and energy value of human milk. Br Med $J$ 1(6119), $1018-1020$.

Malaba LC, Iliff PJ, Nathoo KJ, et al. (2005) Effect of postpartum maternal or neonatal vitamin A supplementation on infant mortality among infants born to HIV-negative mothers in Zimbabwe. Am J Clin Nutr 81, 454-460.

National AIDS Control Programme (2001) AIDS in Kenya: Background, Projections, Impact, Intervention and Policy no. 6. Nairobi: Ministry of Health.

Olson JA (1984) Serum levels of vitamin A and carotenoids as reflectors of nutritional status. J Natl Cancer Inst 73, 1439-1444.

Rahmathullah L, Tielsch JM, Thulasiraj RD, et al. (2003) Impact of supplementing newborn infants with vitamin A on early infant mortality: community based randomised trial in southern India. Br Med J 327(7409), 254.

Rice AL, Stoltzfus RJ, de Francisco A, Chakraborty J, Kjolhede CL \& Wahed MA (1999) Maternal vitamin A or beta-carotene supplementation in lactating Bangladeshi women benefits mothers and infants but does not prevent subclinical deficiency. $J$ Nutr 129, 356-365.

Ross DA (2002) Recommendations for vitamin A supplementation. J Nutr 132, Suppl., 2902S-2906S.

Stoltzfus RJ, Hakimi M, Miller KW, et al. (1993) High dose vitamin A supplementation of breast-feeding Indonesian mothers: effects on the vitamin A status of mother and infant. $J$ Nutr 123, 666-675.

Tanumihardjo SA, Cheng JC, Permaesih D, et al. (1996) Refinement of the modified-relative-dose-response test as a method for assessing vitamin A status in a field setting: experience with Indonesian children. Am J Clin Nutr 64, 966-971. 
Thurnham DI \& Singkamani R (1991) The acute phase response and vitamin A status in malaria. Trans $R$ Soc Trop Med Hyg 85, 194-199.

West KP Jr (2002) Extent of vitamin A deficiency among preschool children and women of reproductive age. J Nutr 132, Suppl., 2857S-2866S

West KP Jr, Katz J, Shrestha SR, et al. (1995) Mortality of infants $<6$ mo of age supplemented with vitamin A: a randomized, doublemasked trial in Nepal. Am J Clin Nutr 62, 143-148.

World Health Organization (1996) Indicators for Assessing Vitamin A Deficiency and their Application in Monitoring and Evaluating Intervention Programmes. WHO/NUT/96.10. Geneva: WHO.
World Health Organization (1998) Safe Vitamin A Dosage During Pregnancy and Lactation. Recommendations and Report of a Consultation. WHO/NUT/98.4. Geneva: WHO.

World Health Organization/CHD (1998) Randomised trial to assess benefits and safety of vitamin A supplementation linked to immunisation in early infancy. WHO/CHD Immunisation-Linked Vitamin A Supplementation Study Group. Lancet 352(9136), 1257-1263.

Zvandasara P, Hargrove JW, Ntozini R, et al. (2006) Mortality and morbidity among postpartum HIV-positive and HIV-negative women in Zimbabwe: risk factors, causes, and impact of singledose postpartum vitamin A supplementation. J Acquir Immune Defic Syndr 43, 107-116. 